NIST

PUBLICATIONS

\title{
New Expressions of Uncertainties for Humidity Calibrations at the National Institute of Standards and Technology
}

Peter H. Huang James R. Whetstone

U.S. DEPARTMENT OF COMMERCE Technology Administration National Institute of Standards and Technology Process Sensing Groups Process Measurements Division Chemical Science and Technology Laboratory Gaithersburg, MD 20899 



\section{New Expressions of Uncertainties for Humidity Calibrations at the National Institute of Standards and Technology}

Peter H. Huang

James R. Whetstone

U.S. DEPARTMENT OF COMMERCE

Technology Administration

National Institute of Standards

and Technology

Process Sensing Groups

Process Measurements Division

Chemical Science and Technology Laboratory

Gaithersburg, MD 20899

June 1994

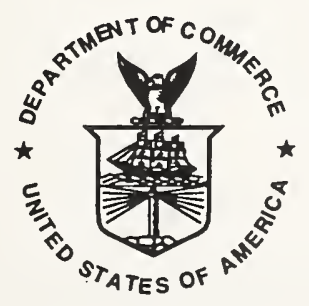

U.S. DEPARTMENT OF COMMERCE

Ronald H. Brown, Secretary

TECHNOLOGY ADMINISTRATION

Mary $L$ Good, Under Secretary for Technology

NATIONAL INSTTTUTE OF STANDARDS

AND TECHNOLOGY

Arat Prabhakar, Director 



\section{NEW EXPRESSIONS OF UNCERTAINTIES FOR HUMIDITY CALIBRATIONS AT THE}

NATIONAL INSTITUTE OF STANDARDS AND TECHNOLOGY

NIST humidity standards are documented in NISTIR 4677, entitled "NIST Calibration Services for Humidity Measurement" [1]. In accordance with a new NIST policy for expressing the uncertainty of measurements [2], previous uncertainties stated in tables 24 and 26 of reference 1 have been revised. Based on the "Guide to the Expression of Uncertainty in Measurement" [3], the systematic error and random error in the pressure and temperature measurements in table 24 of reference 1 were estimated by Type B and Type A evaluations of standard uncertainty, respectively. The Type A and B standard uncertainties are combined into the combined standard uncertainty, $u_{c}$, by the method of the "law of propagation of uncertainty" or the "root-sum-ofsquares" method [2], i.e., $\mathrm{u}_{\mathrm{c}}=\left(\mathrm{u}_{\mathrm{A}}^{2}+\mathrm{u}_{\mathrm{B}}{ }^{2}\right)^{1 / 2}$. The Type A standard uncertainties associated with temperature and pressure measurements given in table 1 are $1 \sigma$ values, thereby differing from the previous $3 \sigma$-random errors given in table 24 of reference 1 .

The previously estimated systematic errors associated with temperature measurements [1] were primarily due to the maximum temperature gradient measured in the final bath of the two-pressure humidity generator which contains the saturator and the test chamber. The uncertainties of enhancement factor listed in table 24 of reference 1 were based on a formalism not consistent with that of reference 2 . To satisfy the new NIST requirement, an analysis was performed on Type B uncertainty components to reflect a triangular distribution [2]. Now the relative combined standard uncertainty, $u_{c r}$, in mixing ratio can be calculated using equation (51) of reference 1 and the subscript $r$ indicates that $u_{c}$ is a relative combined standard uncertainty,

$$
u_{c r}=\left(\frac{u\left(r_{w}\right)}{r_{w}}\right)_{c}=\frac{P_{S}}{P_{s}-f e_{w}}\left[\left(\frac{u\left(e_{w}\right)}{e_{w}}\right)^{2}+\left(\frac{u\left(P_{S}\right)}{P_{s}}\right)^{2}+\left(\frac{u(f)}{f}\right)^{2}\right]^{1 / 2}
$$

or

$$
U_{c, x}=\frac{P_{s}}{P_{s}-f e_{w}}\left[u_{x}^{2}\left(e_{w}\right)+u_{x}^{2}\left(P_{s}\right)+u_{x}^{2}(f)\right]
$$

where

$\mathrm{r}_{\mathrm{w}} \quad=$ saturation mixing ratio

$\mathrm{P}_{\mathrm{s}}=$ saturator pressure

$\mathrm{f}=$ enhancement factor

$\mathrm{e}_{\mathrm{w}} \quad=$ saturation water vapor pressure over a plane surface of the pure phase of liquid water or solid ice at the saturator temperature. 
The experimental uncertainties are given in equations $3-5$.

$$
\begin{gathered}
u_{x}\left(e_{w}\right)=\frac{u\left(e_{w}\right)}{e_{w}}=\text { saturation vapor pressure relative uncertainty } \\
u_{x}\left(e_{w}\right)=\frac{u\left(P_{s}\right)}{P_{s}}=\text { saturtor pressure relative uncertainty } \\
u_{x}(f)=\frac{u(f)}{f}=\text { enhancement factor relative uncertainty }
\end{gathered}
$$

Additionally, the combined uncertainty in temperature measurement is used to calculate standard uncertainties in saturation water vapor pressure based on the International Temperature scale of $1990[4,5]$. Previous data of temperature and water vapor pressure obtained for table 24 of reference 1 were based on the International Practical Temperature Scale of 1968 [6]. The type A and Type B uncertainties of table 1 were used to calculate the experimental uncertainties listed for $u_{r}\left(e_{w}\right), u_{r}\left(P_{s}\right)$, and $u_{r}(f)$. The last column of relative expanded uncertainties is then computed using equation (1).

Furthermore, NIST policy requires that the value of a measureand should be confidently asserted to lie within an interval about a measurement result. The measure of uncertainty intended to meet this requirement is termed expanded uncertainty, $U$, and is obtained by multiplying the combined standard uncertainty, $u_{c}$, by a coverage factor, $k$. A coverage factor of 1,2 , and 3 defines an interval for the value of a measureand having approximate level of confidence 68.3, 95.4 , and 99.7 percent of a normal distribution, respectively.

Under the new NIST policy, a coverage factor of 2 is generally used to provide the expanded uncertainty values. The calculated relative expanded uncertainties in mixing ratio, volume ratio, dew-point temperature, and relative humidity for the NIST two-pressure humidity generator are listed in tables 1 and 2 of this document, and they supersede tables 24 and 26 of reference 1 , respectively. The relative expanded uncertainties associated with humidity parameters are similar in value to those previously listed in reference 1 . For a humidity parameter described by a normal distribution, the relative expanded uncertainty listed in table 2 defines an interval having a level of confidence of approximately 95 percent. 
蒫.

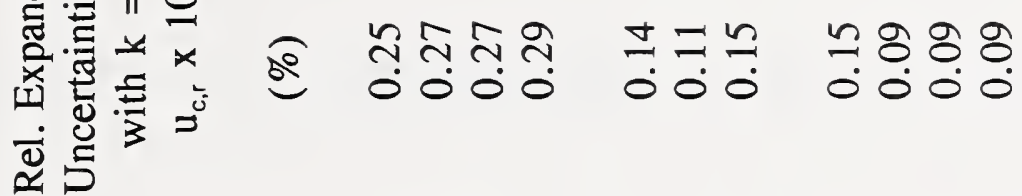

.

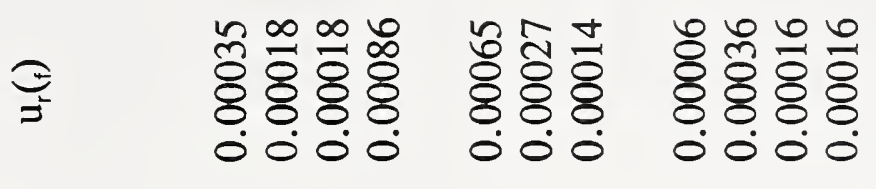

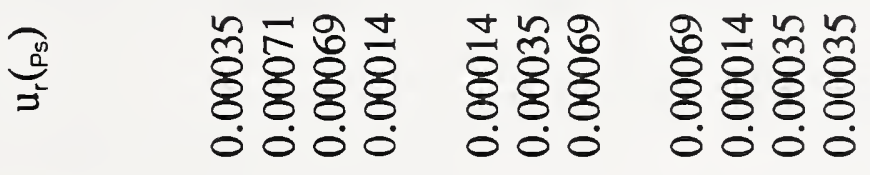

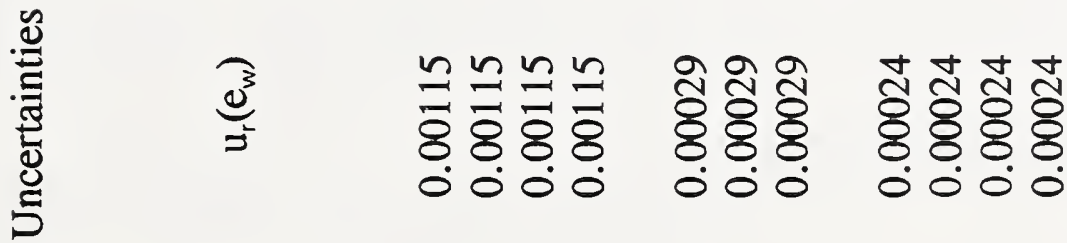

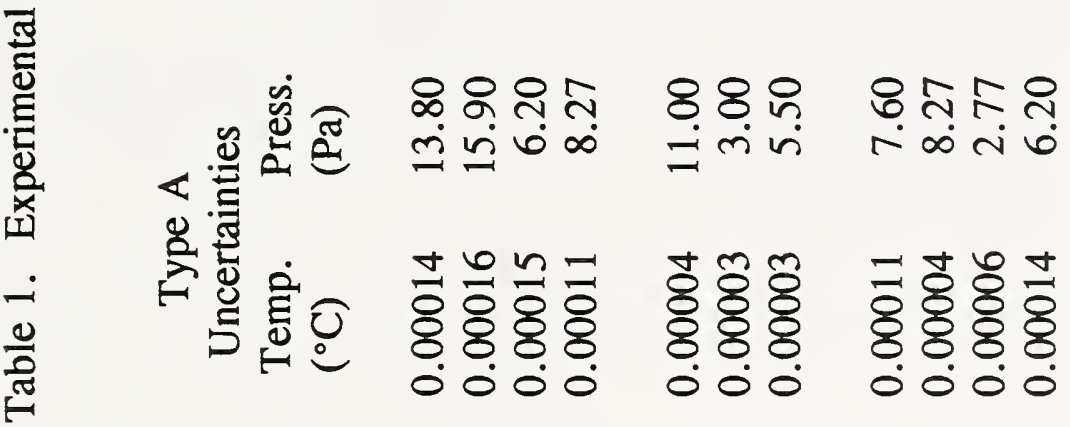

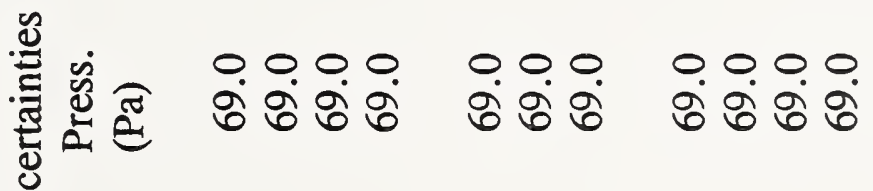

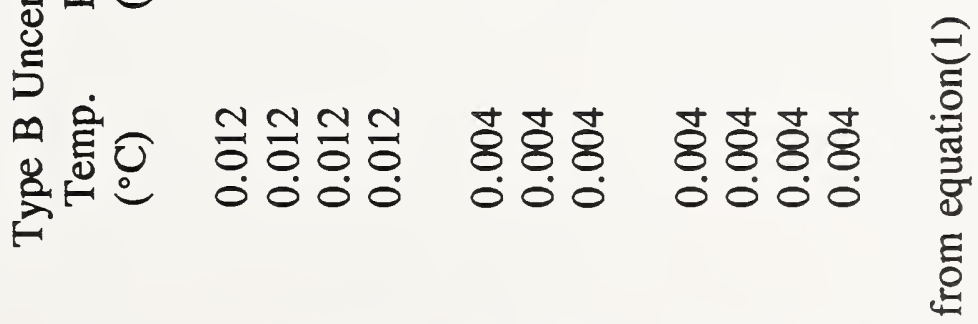

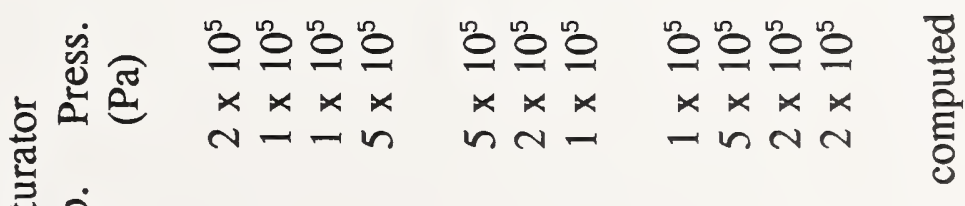

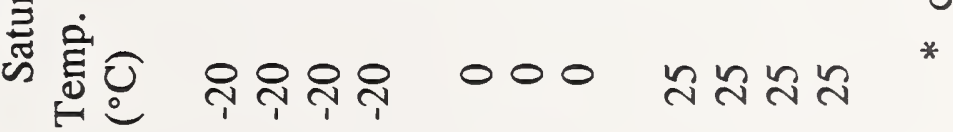


Table 2. NIST Two-Pressure Humidity Generator, Mark 2, Range and Uncertainty

\begin{tabular}{ccc}
\hline Humidity parameter & Range & Expanded \\
Uncertainty, $\mathrm{k}=2$ \\
\hline
\end{tabular}

Mixing ratio, $\mathrm{r}_{\mathrm{w}}$

(g water vapor $/ \mathrm{kg}$ dry air)

$\begin{array}{ll}0.0015 \leq \mathrm{r}_{\mathrm{w}}<0.005 & 1.5 \% \text { of value } \\ 0.005 \leq \mathrm{r}_{\mathrm{w}}<0.1 & 1.0 \% \text { of value } \\ 0.1 \leq \mathrm{r}_{\mathrm{w}}<0.3 & 0.5 \% \text { of value } \\ 0.3 \leq \mathrm{r}_{\mathrm{w}}<515 & 0.3 \% \text { of value }\end{array}$

Volume ratio, $\mathrm{V}(\mathrm{ppm})$

$$
\begin{aligned}
3 & \leq V<10 \\
10 & \leq V<170 \\
170 & \leq V<500 \\
500 & \leq V<820,000
\end{aligned}
$$

$1.5 \%$ of value $1.0 \%$ of value $0.5 \%$ of value

$0.3 \%$ of value

Dew-point temperature, $\mathrm{T}_{\mathrm{d}}\left({ }^{\circ} \mathrm{C}\right)$

$\begin{array}{ll}-70 \leq \mathrm{T}_{\mathrm{d}}<-35 & 0.1 \\ -35 \leq \mathrm{T}_{\mathrm{d}}<+40 & 0.04\end{array}$

Relative humidity, $\mathrm{RH}(\%)$ at test chamber temperature $\mathrm{T}_{\mathrm{c}}\left({ }^{\circ} \mathrm{C}\right)$ of:

$\begin{array}{rlrl}-55 & \leq \mathrm{T}_{c}<-40 & 3-98 & 1.5 \\ -40 & \leq \mathrm{T}_{\mathrm{c}}<-20 & 3-98 & 0.8 \\ -20 & \leq \mathrm{T}_{\mathrm{c}}<0 & 3-98 & 0.4 \\ 0 & \leq \mathrm{T}_{\mathrm{c}}<+40 & 3-98 & 0.2\end{array}$




\section{REFERENCES}

[1] Huang, P.H., "NIST Calibration Services for Humidity Measurement", NISTIR 4677 (October 1991).

[2] Taylor, B.N. and Kuyatt, C.E., "Guidelines for Evaluating and Expressing the Uncertainty of NIST Measurement Results", NIST Technical Note 1297 (1993).

[3] ISO, "Guide to the Expression of Uncertainty in Measurement", ISO Technical Advisory Group 4 (TAG 4) and Working Group 3 (WG 3) (1993)

[4] Preston-Thomas, H., "The International Temperature Scale of 1990 (ITS-90)", Metrologia 27, 3-10 (1990); ibid., 107 (1990).

[5] Huang, P.H., "Thermodynamic Properties of Moist Air Containing 1000 to $5000 \mathrm{ppm}_{\mathrm{v}}$ of Water Vapor", NISTIR 5741, 43-51 (April 1993).

[6] "The International Practical Temperature Scale of 1968, Amended Edition of 1975", Metrologia 12, 7 (1976). 

